\title{
Endothelial progenitors in pulmonary hypertension: new pathophysiology and therapeutic implications
}

\author{
G.P. Fadini*, A. Avogaro*, G. Ferraccioli ${ }^{\#}$ and C. Agostini*
}

ABSTRACT: Pulmonary hypertension is a progressive and disabling disease with as yet unclear pathogenesis, limited treatment options and poor prognosis. This is why the discovery of new pathogenic mechanisms and therapeutic strategies are needed. Endothelial progenitor cells (EPCs) are bone marrow-derived cells involved in endothelial homeostasis, as well as physiological and pathological angiogenesis. Experimental and clinical studies have been conducted to understand the possible contribution of EPCs to the pathogenesis of pulmonary hypertension. Conflicting results have been obtained regarding the protective versus harmful effects of EPCs on the pulmonary vasculature. However, preliminary clinical trials using EPCbased therapies in patients with pulmonary hypertension show benefit of this approach, thus revealing EPCs as potential therapeutic targets.

This review critically summarises the complex and conflicting data on EPCs and pulmonary hypertension, in both humans and animals, putting them into the context of lung (patho)physiology.

The resulting scenario identifies EPCs as a novel and fascinating tool to study pathophysiology and therapy in the setting of pulmonary hypertension.

KEYWORDS: Angiogenesis, endothelium, stem cells

$\mathbf{T}$ he term "pulmonary hypertension" (PH) spans a group of diseases characterised by raised arterial or venous pulmonary pressures [1]. Pulmonary venous hypertension is usually a consequence of myocardial or valve heart disease, and will not be considered in this review. Pulmonary arterial hypertension (PAH) can be idiopathic or associated with chronic conditions, such as connective tissue disorders $[2,3]$. PH can be also associated with hypoxic lung disease, such as chronic obstructive pulmonary disease (COPD), interstitial lung disease, sleep-disordered breathing (e.g. obstructive sleep apnoea syndrome), alveolar hypoventilation disorders, chronic exposure to high altitude, or developmental abnormalities (e.g. bronchopulmonary dysplasia). Another cause of $\mathrm{PH}$ is the chronic thromboembolic obstruction of proximal or distal pulmonary arteries. There is evidence that genetic factors underlie a good proportion of idiopathic PAH: germline mutations of the bone morphogenetic protein (BMP) receptor-2 (BMPR2) were identified in $\sim 40 \%$ of familiar idiopathic
$\mathrm{PAH}$ and $\sim 15 \%$ of sporadic idiopathic PAH [4]. However, a common pathogenetic model for all forms of $\mathrm{PH}$ is lacking and mechanisms are still incompletely defined. Given that the presence of idiopathic or associated PAH is a negative prognostic factor, considerable interest exist in the understanding of the mechanisms that promote $\mathrm{PH}$ development and progression. In this review, we will discuss the available evidence suggesting that endothelial progenitor cells (EPCs) are involved in development or prevention of $\mathrm{PH}$ and represent a novel therapeutic tool. This article is part of a series of review papers focusing on various aspects of pulmonary hypertension [5-13].

\section{ENDOTHELIAL PROGENITOR CELLS}

EPCs were first discovered in 1997 by AsAHARA et al. [14], who identified in the adult human peripheral blood a population of CD34 or kinase insert domain receptor (KDR)-positive cells that were able to differentiate into mature endothelial cells and were involved in neo-vascularisation. This notion challenged the previous concept that

\section{AFFILIATIONS}

${ }^{*}$ Dept of Clinical and Experimental Medicine, University of Padova, Medical School, Padova, and \#Division of Rheumatology, Catholic University of the Sacred Heart, Rome, Italy.

\section{CORRESPONDENCE}

G.P. Fadini

Dipartimento di Medicina Clinica e

Sperimentale

v. Giustiniani 2

35100 Padova

Italy

E-mail: gianpaolofadini@

hotmail.com

Received:

July 162009

Accepted after revision:

Sept 062009 
de novo formation of new blood vessels occurs only in the yolk sac mesoderm during embryonic development. It was soon recognised that EPCs derive from the bone marrow and can be mobilised into the peripheral circulation in response to many stimuli, including tissue ischaemia and vascular damage, through the release of growth factors and cytokines [15]. Once in the bloodstream, EPCs constitute a pool of circulating cells able to form a cellular patch at sites of endothelial denudation, in order to restore endothelial integrity [16]. This action has been demonstrated in several experimental models and is accomplished through the expression of surface adhesion molecules and chemokines receptors [17, 18]. EPCs are also involved in physiological and pathological stimulation of new vessel growth, both de novo (neo-vasculogenesis) or sprouting from pre-existing vessels (neo-angiogenesis), especially in ischaemic tissues. EPCs specifically home to ischaemic sites thanks to the expression of the stromal cell derived factor$1 \alpha /$ CXCR4 chemokine system, proliferate locally and physically integrate into nascent blood vessels, or stimulate resident endothelial cells to do so through secretion of growth factors $[19,20]$. Experimental studies have indeed demonstrated that ex vivo expanded human EPCs, when transplanted into immunocompromised animals, participate in post-ischaemic angiogenesis. Moreover, cell tracking systems employing green fluorescence protein (GFP)-positive bone marrow chimeric animals confirmed that bone marrow-derived endothelial cells physically take part in new vessel formation [21]. Thus, circulating EPCs play two major roles in the cardiovascular system: endothelial healing and neo-angiogenesis. With this background, it is easy to anticipate that a reduction in circulating EPCs would translate into inability to maintain a healthy endothelium and impaired post-ischaemic angiogenesis, favouring development and progression of cardiovascular disease [22]. Actually, there have been several demonstrations that the level of circulating EPCs is directly related to measures of peripheral and coronary endothelial function [23-25]. A significant reduction of circulating EPCs is also associated with the earliest signs of atherosclerotic remodelling, such as increased carotid intima-media thickness [26]. Remarkably, virtually all classical cardiovascular risk factors have been associated with significant reduction or dysfunction of EPCs; such that EPC alterations are now considered to be a major mechanism by which risk factors translate into impaired cardiovascular homeostasis [22]. Even if there is no direct demonstration in humans, circulating EPCs would be the determinant of both endothelial integrity and systemic angiogenic potential, as also suggested by the observation that transplantation of EPC-enriched bone marrow cells restores coronary microvascular function in patients after acute myocardial infarction [27]. The resulting picture is that altered EPCs play a pathogenic role in the early phases of atherogenesis by inhibiting endothelial healing, and in the later phase of atherosclerotic syndromes by inhibiting post-ischaemic angiogenesis. Accumulating evidence that EPC defects are involved in all stages of the atherosclerotic process were the basis for the initiation of cell therapy trials in patients with ischaemic syndromes, yielding some enthusiastic results [28].

This amazingly harmonic scenario has been challenged by the lack of a consensus on the methods to study EPCs [29]. For the purposes of this review, we will not go into excessive technical details, just mentioning that two methods can be used to assess circulating EPCs: flow cytometry and cell culture. Flow cytometry provides a reliable and pure quantitative measure of EPC level, but the exact antigenic phenotype of EPCs is elusive. For a number of technical and biological considerations, the CD34+KDR+ phenotype should still be the preferred antigenic combination, even if CD133+KDR and CD34+CD133+KDR+ cells might be considered to be EPCs as well. In contrast, the CD34+, CD133+ and CD34+CD133+ phenotypes, not including an endothelial marker (KDR, CD31 or Von Willebrand factor), can be simply considered generic circulating progenitors (mostly haematopoietic). Cell culture protocols allow isolation and expansion of EPCs for functional analyses in vitro and in vivo. Several protocols have been described, which can be roughly divided into short-term cultures (early EPCs) and long-term cultures (late EPCs) of endothelial(-like) cells from a starting heterogeneous population of peripheral blood mononuclear cells. Early EPCs display features of immune cells and mainly include macrophages assuming an endothelial-like phenotype [30]; essentially, they act by releasing growth factors and cytokines, rather than physically integrating into the endothelium [20]. Late EPCs acquire a complete endothelial phenotype and maintain a high proliferative potential; they are believed to directly participate in endothelial healing and angiogenesis [31]. These cells are also called endothelial colony forming cells (ECFC). Unfortunately, the use of different protocols to study EPCs can yield profoundly different or even opposite results, limiting advances in our knowledge of the pathophysiological role of these cells [32]. Some authors recommend that the early EPC culture should be definitely discarded, as it essentially leads to the isolation of inflammatory cells. However, recent studies on the development of the vascular and haematopoietic systems have clarified that haematopoietic cells arise from a so-called haemogenic endothelium [33]. Given the similarities between EPCs and the embryoid angioblast, we cannot rule out that multiple inter-relations between haematopoietic and endothelial progenitors also exist in the adult life, a notion that could reconcile the multifaceted and dynamic phenotypes of EPCs in culture.

Despite these limitations, there is considerable agreement that EPCs contribute to endothelial homeostasis and neo-angiogenesis, which might have important implications in $\mathrm{PH}$ [34]. However, it is possible that methodological differences in EPC assays contribute to the conflicting results obtained in studies assessing the harmful versus protective role of EPC in $\mathrm{PH}$.

\section{ENDOTHELIAL DAMAGE IN THE PULMONARY AND SYSTEMIC CIRCULATIONS}

The most recent and comprehensive pathogenic theories on $\mathrm{PH}$ put the endothelium at the centre of the scene [2, 35]. Endothelial cells that line the vasculature form a physiological barrier against noxious agents from the bloodstream [36, 37]. A healthy endothelium promotes anti-aggregation, fibrinolysis and maintenance of normal vasodilation. Endothelial cells secrete several mediators that can cause either vasoconstriction, such as endothelin- 1 and thromboxane A2, or vasodilation such as nitric oxide (NO), prostacyclin and endotheliumderived hyperpolarising factor. The enzyme deputed to NO synthesis (endothelial NO synthase; eNOS) is actually the master gene regulator in endothelial cells, being involved in 
endothelial development and survival. A functional or anatomical loss of endothelial integrity (known as endothelial dysfunction or damage) is associated with increased blood coagulability, platelet aggregation and vasoconstriction. All these alterations can have profoundly detrimental effects on both the systemic and pulmonary arterial systems. It is generally agreed that endothelial dysfunction in the systemic circulation is the first step of the atherosclerotic process, ultimately leading to the formation of the lipid-rich plaque [38]. Similarly, endothelial damage or dysfunction is considered a trigger for the development of $\mathrm{PH}$, through many disparate mechanisms [35]. There may be several causes for endothelial damage to develop and subsequently to cause $\mathrm{PH}$ [39]. Hypoxaemia, which may be present in patients with chronic lung disease, causes electron leakage from the respiratory chain, thus inducing oxygen radical generation and oxidative stress. Reactive oxygen species then quench NO, impair endothelial regulation of vascular tone and turn the endothelial layer into a pro-coagulant and adhesive surface. Genetic mutations and microsatellite instability, such as those encountered in some forms of idiopathic PAH, can actually trigger endothelial damage by slowing endothelial turnover and reducing its survival [40]. Autoimmunity, as well as local and systemic inflammation, induce expression of adhesion molecules on the surface of endothelial cells, and activate intracellular signalling pathways that culminate in the classic features of endothelial dysfunction. Once endothelial dysfunction is established through these many mechanisms, the way to pulmonary vascular remodelling is set forth. The consequences of endothelial dysfunction include: 1) imbalance between vasodilatory (e.g. NO) and vasoconstrictive (e.g. endothelin) mediators; 2) leukocyte adhesion, chemotaxis and production of growth factors; 3) detachment of endothelial cells and exposure of subendothelium to the action of growth factors and coagulation; and 4) deranged response to injury and enhanced intimal proliferation. This will finally translate into vasoconstriction, smooth muscle and adventitial proliferation, ultimately leading to vascular luminal obliteration and $\mathrm{PH}$ [41]. There are striking similarities between this pathogenetic scenario of $\mathrm{PH}$ and the atherogenetic process, which also involves endothelial damage, vascular adhesion, coagulation and inflammation. The reasons why, starting from similar early endothelial alterations, a fibroproliferative lesion develops in the pulmonary circulation and a lipid-rich plaque develops in the systemic circulation are unclear. However, this is probably due to differences in endothelial cell phenotype and in the physiological regulation of the pulmonary and systemic circulations. Indeed, despite both circulations receiving the whole cardiac output, the systemic circulation is a highpressure, high-resistance, low-compliance system governed by the Poiseuille law, while the pulmonary circulation is a lowpressure, low-resistance, high-compliance system resembling a vascular waterfall $[42,43]$. Moreover, response to hypoxia is the opposite in the pulmonary to that in the systemic arterial beds $[44,45]$. Hypoxia causes vasodilation in the systemic microcirculation, as a result of the production of hypoxic metabolites, such as lactate. In contrast, hypoxia causes pulmonary arterial vasoconstriction, in order to make the ventilation/perfusion ratio uniform and preserve adequate blood oxygenation. Despite these profound differences, our current knowledge supports the notion that alterations of the endothelial layer are the primum movens of both atherosclerosis and $\mathrm{PH}$.

\section{ANGIOGENESIS IN PULMONARY AND SYSTEMIC CIRCULATION}

The highly compliant pulmonary circulation sustains doublings of cardiac output without abrupt increases in pulmonary pressures because pulmonary resistances lower with increasing blood flow, just like a vascular waterfall [43]. This is accomplished through recruitment of a large network of capillaries, which are not perfused in basal conditions and form a functional pulmonary vascular reserve [46]. Thus, it is intuitive that rarefaction of the pulmonary capillary network would reduce the pulmonary vascular reserve and increase pulmonary pressures, especially in the case of increased demand, such as during physical efforts $[47,48]$. This scenario is best represented by the patient with emphysema, in whom chronic hypoxia and loss of septum-associated capillaries lead to $\mathrm{PH}$, which manifests or worsens during exercise. The most obvious mechanism for development of this form of $\mathrm{PH}$ appears to be vascular rarefaction, while expansion of the capillary bed through neo-angiogenesis would be intuitively desirable in this setting to restore the pulmonary microvascular bed and lower pulmonary pressures [49].

An almost opposite pathological scenario is set out in idiopathic PAH, in which there is no evidence of anatomical microvascular loss and alveolar capillaries appear quite normal in most of the lung. Rather, plexiform lesions show complex angioproliferative aspects, and increased neo-angiogenesis seems to play a negative pathogenic role [50]. However, it is not clear if such lesions are causatively related to increased pulmonary pressures or simply represent a disease "epiphenomenon", as a misguided and unsuccessful attempt of angiogenesis to compensate for proximal arteriolar occlusion. If these lesions were pathogenic, inhibition of angiogenesis might be beneficial to block lesion formation and slow disease progression.

In the middle between these two opposite forms of $\mathrm{PH}$, there are lung diseases in which angiogenesis and vascular rarefaction occur at the same time [49]. For instance, bronchial asthma shares some features of pulmonary emphysema but is associated with bronchial submucosal neo-angiogenesis [51], while acute lung injury and adult respiratory distress syndrome display features of both capillary involution and neo-angiogenesis. Thus, it seems very difficult to discern a univocal role of angiogenesis in the development or progression of PH. Experimental intervention studies do not resolve this issue: in some studies, blocking angiogenesis was associated with improvement in hypoxic PH [52], while in other studies, stimulation of angiogenesis ameliorated hypoxic $\mathrm{PH}$ [53], and there is an ongoing controversy as to whether chronic hypoxia leads to loss of pulmonary vasculature [54].

Intriguingly, a similar Janus face of angiogenesis has been described in the systemic circulation [55]. Most forms of chronic atherosclerotic syndromes, such as ischaemic heart disease, peripheral arterial disease and cerebrovascular disease, are caused by reduced perfusion of terminal circulations, due to plaque stenosis. In these conditions, angiogenesis is strongly inhibited by the risk factors, such as hyperglycaemia 
and smoking, while many therapeutic strategies are aimed at promoting angiogenesis and restoring blood flow. In contrast, neo-angiogenesis is undesirable inside atherosclerotic plaques because it promotes accumulation of inflammatory cells within the plaque and the leaky neo-capillaries increase the risk of plaque haemorrhage and rupture $[22,56]$. The existence of novel therapies to block plaque angiogenesis supports the potential relevance of this mechanism.

Thus, the parallel between the pulmonary and systemic circulation for the role of angiogenesis in disease development is striking and deserves further investigation.

\section{EPCS IN PH}

As mentioned previously, endothelial damage and angiogenesis may play important roles in the pathogenesis of $\mathrm{PH}$ as well as in the development of atherosclerosis and other cardiovascular diseases. Most early studies on the clinical implications of EPCs have focused on the systemic circulation, while an interest in the relationships between EPCs and $\mathrm{PH}$ is more recent [57].

\section{Clinical observational studies}

In a comprehensive clinical-pathological study, AsOsINGH et al. [58] assessed early and late EPCs in control subjects and in patients with idiopathic PAH. They found significantly increased early (or "monocytic") EPCs in PAH patients compared with controls, while there was no difference in the amount of late EPCs (or ECFC) in peripheral blood and in pulmonary arteries. In addition, they reported that the level of circulating CD34+CD133 cells, determined by flow cytometry, was directly correlated to pulmonary arterial pressures in PAH patients. PEINADO et al. [59] showed that the amount of resident CD133+ cells, which were considered precursors of EPCs, is higher in pulmonary arteries obtained from COPD patients than from controls subjects, and correlates with contraction response of these arterial segments to potassium chloride (a surrogate hypoxic stimulus). The homing of CD34+KDR+ EPCs to diseased pulmonary arteries has also been demonstrated in a study of endarterectomised tissue from patients with chronic thromboembolic PH [60]. These studies can be interpreted as the demonstration of a negative pathogenic role of EPCs in $\mathrm{PH}$, in compliance with the hypothesis that angiogenesis favours development and progression of $\mathrm{PH}$. However, it cannot be ruled out that increased EPCs reflect an unsuccessful attempt to repair the damaged pulmonary endothelium. In another study, JuNHUI et al. [61] found decreased CD133+KDR+ cell levels, and reduced and dysfunctional early EPCs in idiopathic PAH patients compared with controls. Similar results were obtained by DiLLER et al. [62], who showed low levels of CD34+KDR+ cells in patients with either Eisenmenger syndrome or idiopathic PAH. Studying patients with idiopathic pulmonary fibrosis, we found that patients with associated $\mathrm{PH}$ displayed significantly lower levels of circulating CD34+CD133+KDR+ EPCs compared with idiopathic pulmonary fibrosis patients without PH [63]. Hypoxia is one concurring mechanism in the development of associated $\mathrm{PH}$ [64]. We have previously shown that arterial oxygen tension is negatively correlated with circulating CD34+CD133+KDR+ EPC levels and directly correlated with blood haemoglobin concentration [65], suggesting an attempt to compensate EPC mobilisation induced by hypoxia through hypoxia-sensing systems, such as erythropoietin [66]. Depletion of circulating EPCs has also been found in patients with COPD, who are at risk of developing associated PH [67]. One interesting study explored the effects of BMPR2 on mature pulmonary endothelial cells and on early EPCs isolated either from idiopathic PAH patients or from healthy controls. Treatment with BMPR2 agonists increased survival of endothelial cells and healthy EPCs. In contrast, in EPCs from PAH patients, there was either a reduced survival or enhanced apoptosis in response to BMPs [68]. In another study, late cultured EPCs from idiopathic PAH patients with BMPR2 mutation showed a hyperproliferative phenotype with impaired ability to form vascular networks [69]. Given the role of loss-of-function mutations of BMPR2 in idiopathic $\mathrm{PAH}$, it is possible that disrupted BMPR2 signalling contributes to both the initial microvascular damage and the subsequent reactive arterial remodeling in the remaining arteriolar and arterial bed. The formation of immature (micro)vessels by incompetent EPCs might be harmful in the pulmonary circulation, as seen in the atherosclerotic plaque.

However, on the basis of these observational data, it is difficult to define a univocal role of EPCs in the setting of idiopathic $\mathrm{PAH}$ or associated $\mathrm{PH}$, possibly due to differences among studies in EPC methods and/or disease stage.

\section{Animal observational studies}

As shown by DAVIE et al. [70], hypoxia-induced PH in calves is characterised by an enhanced development of perfused vasa vasorum, consistent with a neo-angiogenetic process. Interestingly, these vasa vasorum often stained positive for c-kit, a marker of bone marrow-derived cells. In parallel, DAVIE et al. [70] showed that c-kit+ progenitor cells were reduced within bone marrow and increased in peripheral blood, indirectly suggesting that progenitor cell mobilisation contributes to the development of c-kit+ neovessels. Using a GFPpositive bone marrow chimeric mouse model, HAYASHIDA et al. [71] confirmed that bone marrow cells locate at sites of remodelling pulmonary arteries in hypoxia-induced $\mathrm{PH}$, but that they co-express markers of smooth muscle cells rather than endothelial markers. Interestingly, MARSBOOM et al. [72] found that early EPCs isolated from mice with hypoxia-induced $\mathrm{PH}$ show defective pro-angiogenic activities in comparison to EPCs from control mice when transplanted into nude mouse ischaemic hind limbs, thus, providing evidence for a functional EPC impairment in hypoxic PH. Therefore, it appears that compensatory EPC mobilisation and recruitment may actually occur in hypoxic $\mathrm{PH}$, but that this might not be sufficient to prevent disease development because EPCs are dysfunctional. The fact that EPC mobilisation is a protective compensatory attempt rather than a pathogenic event is also supported by the observation that deletion of erythropoietin receptor in nonerythroid cells worsens histopathological features of hypoxiainduced PH compared to wild-type mice [73]. Indeed, worse PH in EPOR-/- mice was associated with completely inhibited CD133+KDR+ EPC mobilisation.

\section{Animal intervention studies}

To gain further insights into the potential role of EPCs in $\mathrm{PH}$, studies attempting to prevent or reverse $\mathrm{PH}$ with EPC 
administration have been devised. In a study of hypoxiainduced $\mathrm{PH}$, transplantation of Sca1+KDR+CXCR4+ cultured early EPCs failed to reverse vascular remodelling and changes in pulmonary haemodynamics [72]. In another study, intravenous administration of bone marrow cells failed to prevent an increase in right ventricular systolic pressure and arterial muscularisation in hypoxic PH. However, RAOUL et al. [74] showed that infusion of the same cells was effective in preventing $\mathrm{PH}$ induced by the administration of the endothelial toxin monocrotaline. Similar results were obtained by $\mathrm{ZHAO}$ et al. [75] showing that bone marrow-derived endothelial-like progenitor cells were effective in preventing and reversing monocrotaline-induced $\mathrm{PH}$. The exact bone marrow cell type that is needed to treat $\mathrm{PH}$ is still undefined. For instance, mesenchymal stem cells (MSC) were also able to attenuate monocrotaline-induced $\mathrm{PH}$ and improve pulmonary endothelial function [76]. However, although MSC assumed endothelial and smooth muscle phenotypes, they did not directly integrate into the pulmonary vasculature, supporting the theory that they act through a paracrine mechanism. The paracrine hypothesis is also supported by the observation that EPCs transfected with the potent vasodilator adrenomedullin were more effective than non-transfected EPCs in reversing features of monocrotaline-induced $\mathrm{PH}$ [77]. Taken together, these data show that EPC administration is effective when $\mathrm{PH}$ derives from a primary endothelial damage, while it seems ineffective when $\mathrm{PH}$ is mediated by hypoxia. This observation suggests that monocrotaline $\mathrm{PH}$ may be a better animal model than hypoxic $\mathrm{PH}$ to study novel therapies, and it also indicates that endothelial damage may be more important than hypoxia in the pathogenesis of $\mathrm{PH}$.

\section{Clinical trials}

In the last 5 yrs, protocols of therapeutic angiogenesis with EPC-enriched cell products have been developed to treat acute and chronic ischaemic cardiovascular syndromes, with the attempt to restore blood flow and reduce organ damage. Although expectations created by animal experience were not fully met [78], meta-analysis showed benefits of cell therapy approaches in patients with myocardial infarction or peripheral arterial disease [28, 79]. The somehow positive results of such studies, coupled with the hint of efficacy in pre-clinical models of $\mathrm{PH}$, stimulated the design of clinical trials of cell therapy in patients with $\mathrm{PAH}$ [80]. Idiopathic $\mathrm{PAH}$ can be a dramatic, rapidly progressive disease, with little therapeutic options and poor prognosis, which often involves young patients. Thus, the identification of novel strategies to treat this condition is of paramount importance for clinicians in charge. The first human study was a prospective, randomised trial comparing the effects of ex vivo cultured early EPC transplantation plus conventional therapy with those of conventional therapy alone in 31 patients with idiopathic PAH [81]. The

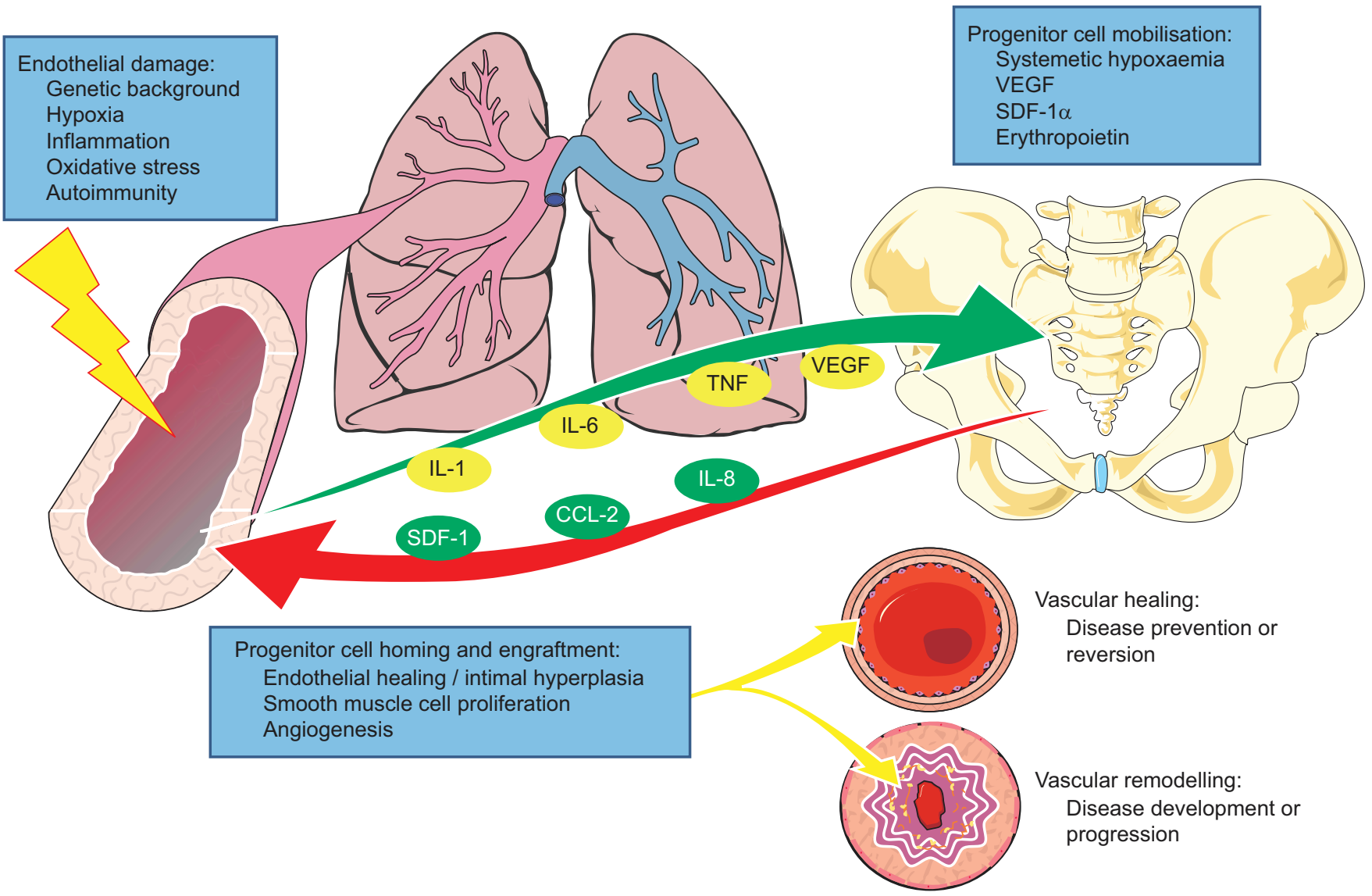

FIGURE 1. The endothelial progenitor cell loop in the pathobiology of pulmonary hypertension. Possible contribution to disease development or vascular healing IL: interleukin; TNF: tumour necrosis factor; VEGF: vascular endothelial growth factor; SDF: stromal cell derived factor; CCL: chemokine (C-C motif) ligand. 
authors showed that cell therapy significantly improved exercise tolerance and pulmonary haemodynamics compared with conventional therapy. Almost simultaneously, a pilot, open-label, nonrandomised trial showed that EPC transplantation was associated with significant improvements in exercise capacity, New York Heart Association functional class, and pulmonary haemodynamics in children with idiopathic PAH [82]. It should be noted that these two trials are from the same Chinese research group and they still need to be confirmed and reproduced elsewhere. Searching the ClinicalTrials.gov database, we found two ongoing trials of cell therapy in $\mathrm{PAH}$ patients, which are being conducted in China (NCT00372346) and Canada (NCT00469027), the results of which will be available in the next couple of years. Thus, these early studies show efficacy of EPC therapy in PAH treatment, but many questions still have to be answered. For instance, it is not clear which is the best cell source (bone marrow versus peripheral blood) and the best cell type (endothelial or haematopoietic progenitor cells or MSC) to be used; we still do not know whether cell therapy is effective in idiopathic PAH alone or in associated $\mathrm{PH}$ as well, and which is the best disease stage for cell therapy to be applied. In addition to these innovative strategies of cell therapy, there are other ways to improve endogenous EPC level and function. A variety of drugs with pleiotropic cardiovascular effects have shown efficacy in increasing EPC levels, through mobilisation or reduced apoptosis, and improve EPC function through several different intracellular pathways [22]. Among these, the hydroxylmethyl-glutaryl-CoA inhibitors (statins) potently stimulate EPC mobilisation, survival and homing, mainly through an eNOS-dependent mechanism [83, 84]. Interestingly, pre-clinical studies suggest that statins might be beneficial in the setting of experimental $\mathrm{PH}[85,86]$, even if there is no demonstration that this is mediated by EPC stimulation. Phosphodiesterase V inhibitors, such as sildenafil, have shown a strikingly rapid capacity to increase EPC levels [87]. Consistently, idiopathic PAH patients on sildenafil had higher EPC levels than nonsildenafil users [62], suggesting that the effects of this drug on pulmonary haemodynamics may be mediated, at least in part, by EPCs.

\section{CONCLUSIONS}

Herein, we have reviewed the available evidence indicating that EPCs are involved in the pathophysiology of idiopathic $\mathrm{PAH}$ and other forms of $\mathrm{PH}$. We have discussed how endothelial homeostasis and angiogenesis, which are intimately linked to EPC biology, may intervene in the pathogenesis of PH. While observational human and animal studies are inconclusive on the negative or protective role of EPCs against $\mathrm{PH}$ (fig. 1), intervention studies appear to demonstrate that EPCs exert favourable effects against $\mathrm{PH}$ development and/or progression. Further studies are needed for a deeper understanding of the processes that regulate EPCs in PH and on the mechanisms by which EPCs would improve pulmonary haemodynamics. Nonetheless, EPCs are a novel and fascinating tool by which to study pathophysiology and novel therapies in $\mathrm{PH}$ patients.

\section{STATEMENT OF INTEREST}

None declared.

\section{REFERENCES}

1 Proceedings of the 4th World Symposium on Pulmonary Hypertension, February 2008, Dana Point, California, USA. J Am Coll Cardiol 2009; 54: Suppl. 1, S1-S117.

2 Farber HW, Loscalzo J. Pulmonary arterial hypertension. N Engl J Med 2004; 351: 1655-1665.

3 Hoeper MM. Definition, classification, and epidemiology of pulmonary arterial hypertension. Semin Respir Crit Care Med 2009; 30: 369-375.

4 Lane KB, Machado RD, Pauciulo MW, et al. Heterozygous germline mutations in BMPR2, encoding a TGF- $\beta$ receptor, cause familial primary pulmonary hypertension. Nat Genet 2000; 26: 81-84.

5 Hoeper MM, Dinh-Xuan AT. Pulmonary hypertension: basic concepts and practical management. Eur Respir J 2008; 31: 236-237.

6 Dupuis J, Hoeper MM. Endothelin receptor antagonists in pulmonary arterial hypertension. Eur Respir J 2008; 31: 407-415.

7 Gomberg-Maitland M, Olschewski H. Prostacyclin therapies for the treatment of pulmonary arterial hypertension. Eur Respir J 2008; 31: 891-901.

8 Wilkins MR, Wharton J, Grimminger F, et al. Phosphodiesterase inhibitors for the treatment of pulmonary hypertension. Eur Respir J 2008; 32: 198-209.

9 Behr J, Ryu JH. Pulmonary hypertension in interstitial lung disease. Eur Respir J 2008; 31: 1357-1367.

10 Warwick G, Thomas PS, Yates DH. Biomarkers in pulmonary hypertension. Eur Respir J 2008; 32: 503-512.

11 Chaouat A, Naeije R, Weitzenblum E. Pulmonary hypertension in COPD. Eur Respir J 2008; 32: 1371-1385.

12 Montani D, Price LC, Dorfmuller P, et al. Pulmonary venoocclusive disease. Eur Respir J 2009; 33: 189-200.

13 Peacock AJ, Naeije R, Galie N, et al. End-points and clinical trial design in pulmonary arterial hypertension: have we made progress? Eur Respir J 2009; 34: 231-242.

14 Asahara T, Murohara T, Sullivan A, et al. Isolation of putative progenitor endothelial cells for angiogenesis. Science 1997; 275: 964-967.

15 Takahashi T, Kalka C, Masuda H, et al. Ischemia- and cytokineinduced mobilization of bone marrow-derived endothelial progenitor cells for neovascularization. Nat Med 1999; 5: 434-438.

16 Rosenzweig A. Endothelial progenitor cells. N Engl J Med 2003; 348: 581-582.

17 Shiba Y, Takahashi M, Yoshioka T, et al. M-CSF accelerates neointimal formation in the early phase after vascular injury in mice: the critical role of the SDF-1-CXCR4 system. Arterioscler Thromb Vasc Biol 2007; 27: 283-289.

18 Werner N, Junk S, Laufs U, et al. Intravenous transfusion of endothelial progenitor cells reduces neointima formation after vascular injury. Circ Res 2003; 93: e17-e24.

19 Ceradini DJ, Kulkarni AR, Callaghan MJ, et al. Progenitor cell trafficking is regulated by hypoxic gradients through HIF-1 induction of SDF-1. Nat Med 2004; 10: 858-864.

20 Heil M, Ziegelhoeffer T, Mees B, et al. A different outlook on the role of bone marrow stem cells in vascular growth. Bone marrow delivers software not hardware. Circ Res 2004; 94: 573-574.

21 Tepper OM, Capla JM, Galiano RD, et al. Adult vasculogenesis occurs through in situ recruitment, proliferation, and tubulization of circulating bone marrow-derived cells. Blood 2005; 105: 1068-1077.

22 Fadini GP, Agostini C, Sartore S, et al. Endothelial progenitor cells in the natural history of atherosclerosis. Atherosclerosis 2007; 194: 46-54.

23 Hill JM, Zalos G, Halcox JP, et al. Circulating endothelial progenitor cells, vascular function, and cardiovascular risk. $N$ Engl J Med 2003; 348: 593-600.

24 Huang PH, Chen YH, Chen YL, et al. Vascular endothelial function and circulating endothelial progenitor cells in patients with cardiac syndrome X. Heart 2007; 93: 1064-1070. 
25 Werner N, Wassmann S, Ahlers P, et al. Endothelial progenitor cells correlate with endothelial function in patients with coronary artery disease. Basic Res Cardiol 2007; 102: 565-571.

26 Fadini GP, Coracina A, Baesso I, et al. Peripheral blood CD34+KDR+ endothelial progenitor cells are determinants of subclinical atherosclerosis in a middle-aged general population. Stroke 2006; 37: 2277-2282.

27 Schachinger V, Assmus B, Honold J, et al. Normalization of coronary blood flow in the infarct-related artery after intracoronary progenitor cell therapy: intracoronary Doppler substudy of the TOPCARE-AMI trial. Clin Res Cardiol 2006; 95: 13-22.

28 Lipinski MJ, Biondi-Zoccai GG, Abbate A, et al. Impact of intracoronary cell therapy on left ventricular function in the setting of acute myocardial infarction: a collaborative systematic review and meta-analysis of controlled clinical trials. J Am Coll Cardiol 2007; 50: 1761-1767.

29 Fadini GP, Baesso I, Albiero $\mathrm{M}$, et al. Technical notes on endothelial progenitor cells: ways to escape from the knowledge plateau. Atherosclerosis 2008; 197: 496-503.

30 Rohde E, Bartmann C, Schallmoser K, et al. Immune cells mimic the morphology of endothelial progenitor colonies in vitro. Stem Cells 2007; 25: 1746-1752.

31 Yoder MC, Mead LE, Prater D, et al. Redefining endothelial progenitor cells via clonal analysis and hematopoietic stem/ progenitor cell principals. Blood 2007; 109: 1801-1809.

32 Leor J, Marber M. Endothelial progenitors: a new Tower of Babel? J Am Coll Cardiol 2006; 48: 1588-1590.

33 Chen MJ, Yokomizo T, Zeigler BM, et al. Runx1 is required for the endothelial to haematopoietic cell transition but not thereafter. Nature 2009; 457: 887-891.

34 Fadini GP, Schiavon M, Avogaro A, et al. The emerging role of endothelial progenitor cells in pulmonary hypertension and diffuse lung diseases. Sarcoidosis Vasc Diffuse Lung Dis 2007; 24: 85-93.

35 Budhiraja R, Tuder RM, Hassoun PM. Endothelial dysfunction in pulmonary hypertension. Circulation 2004; 109: 159-165.

36 Brevetti G, Schiano V, Chiariello M. Endothelial dysfunction: a key to the pathophysiology and natural history of peripheral arterial disease? Atherosclerosis 2008; 197: 1-11.

37 Avogaro A, Fadini GP, Gallo A, et al. Endothelial dysfunction in type 2 diabetes mellitus. Nutr Metab Cardiovasc Dis 2006; 16: Suppl. 1, S39-S45.

38 Ross R, Glomset J, Harker L. Response to injury and atherogenesis. Am J Pathol 1977; 86: 675-684.

39 Yuan JX, Rubin LJ. Pathogenesis of pulmonary arterial hypertension: the need for multiple hits. Circulation 2005; 111: 534-538.

40 Tuder RM, Cool CD, Yeager M, et al. The pathobiology of pulmonary hypertension. Endothelium. Clin Chest Med 2001; 22: 405-418.

41 Chan SY, Loscalzo J. Pathogenic mechanisms of pulmonary arterial hypertension. J Mol Cell Cardiol 2008; 44: 14-30.

42 West JB. Pulmonary physiology and pathophysiology. Philadelphia, Lippincott Williams, 2007.

43 Permutt S, Bromberger-Barnea B, Bane HN. Alveolar pressure, pulmonary venous pressure, and the vascular waterfall. Med Thorac 1962; 19: 239-260.

44 Tucker A. Pulmonary and systemic vascular responses to hypoxia after chemical sympathectomy. Cardiovasc Res 1979; 13: 469-476.

45 Vanhoutte PM, Miller VM. Heterogeneity of endothelium-dependent responses in mammalian blood vessels. J Cardiovasc Pharmacol 1985; 7: Suppl. 3, S12-S23.

46 Reeves JT, Linehan JH, Stenmark KR. Distensibility of the normal human lung circulation during exercise. Am J Physiol Lung Cell Mol Physiol 2005; 288: L419-L425.

47 Lucas CL. Fluid mechanics of the pulmonary circulation. Crit Rev Biomed Eng 1984; 10: 317-393.

48 Donnelly PM, Daxini BV, Bye PT. The upper limit of alveolar capillary recruitment in a young man with lung growth impairment. Eur Respir J 1994; 7: 1371-1375.
49 Hopkins N, McLoughlin P. The structural basis of pulmonary hypertension in chronic lung disease: remodelling, rarefaction or angiogenesis? J Anat 2002; 201: 335-348.

50 Tuder RM, Chacon M, Alger L, et al. Expression of angiogenesisrelated molecules in plexiform lesions in severe pulmonary hypertension: evidence for a process of disordered angiogenesis. J Pathol 2001; 195: 367-374.

51 Asosingh K, Swaidani S, Aronica M, et al. Th1- and Th2-dependent endothelial progenitor cell recruitment and angiogenic switch in asthma. J Immunol 2007; 178: 6482-6494.

52 Hyvelin JM, Howell K, Nichol A, et al. Inhibition of Rho-kinase attenuates hypoxia-induced angiogenesis in the pulmonary circulation. Circ Res 2005; 97: 185-191.

53 Howell K, Costello CM, Sands M, et al. L-Arginine promotes angiogenesis in the chronically hypoxic lung: a novel mechanism ameliorating pulmonary hypertension. Am J Physiol Lung Cell Mol Physiol 2009; 296: L1042-L1050.

54 Rabinovitch M, Chesler N, Molthen RC. Point:Counterpoint chronic hypoxia-induced pulmonary hypertension does/does not lead to loss of pulmonary vasculature. J Appl Physiol 2007; 103: 1449-1451.

55 Avogaro A, Fadini GP. The Janus face of nicotinic angiogenesis. J Am Coll Cardiol 2006; 48: 2561-2563.

56 Ribatti D, Levi-Schaffer F, Kovanen PT. Inflammatory angiogenesis in atherogenesis - a double-edged sword. Ann Med 2008; 40: 606-621.

57 Fadini GP, Avogaro A, Agostini C. Pathophysiology of circulating progenitor cells in pulmonary disease and parallels with cardiovascular disease. Am J Respir Cell Mol Biol 2006; 35: 403-404.

58 Asosingh K, Aldred MA, Vasanji A, et al. Circulating angiogenic precursors in idiopathic pulmonary arterial hypertension. Am J Pathol 2008; 172: 615-627.

59 Peinado VI, Ramirez J, Roca J, et al. Identification of vascular progenitor cells in pulmonary arteries of patients with chronic obstructive pulmonary disease. Am J Respir Cell Mol Biol 2006; 34: 257-263.

60 Yao W, Firth AL, Sacks RS, et al. Identification of putative endothelial progenitor cells in endarterectomized tissue of patients with chronic thromboembolic pulmonary hypertension. Am J Physiol Lung Cell Mol Physiol 2009; 296: L870-L878.

61 Junhui Z, Xingxiang W, Guosheng F, et al. Reduced number and activity of circulating endothelial progenitor cells in patients with idiopathic pulmonary arterial hypertension. Respir Med 2008; 102: 1073-1079.

62 Diller GP, van Eijl S, Okonko DO, et al. Circulating endothelial progenitor cells in patients with Eisenmenger syndrome and idiopathic pulmonary arterial hypertension. Circulation 2008; 117: 3020-3030.

63 Fadini GP, Schiavon M, Rea F, et al. Depletion of endothelial progenitor cells may link pulmonary fibrosis and pulmonary hypertension. Am J Respir Crit Care Med 2007; 176: 724-725.

64 Burger CD. Pulmonary hypertension in COPD: a review and consideration of the role of arterial vasodilators. COPD 2009; 6: 137-144.

65 Fadini GP, Schiavon M, Cantini M, et al. Circulating progenitor cells are reduced in patients with severe lung disease. Stem Cells 2006; 24: 1806-1813.

66 Bahlmann FH, De Groot K, Spandau JM, et al. Erythropoietin regulates endothelial progenitor cells. Blood 2004; 103: 921-926.

67 Palange P, Testa U, Huertas A, et al. Circulating haemopoietic and endothelial progenitor cells are decreased in COPD. Eur Respir J 2006; 27: 529-541.

68 Teichert-Kuliszewska K, Kutryk MJ, Kuliszewski MA, et al. Bone morphogenetic protein receptor-2 signaling promotes pulmonary arterial endothelial cell survival: implications for loss-of-function mutations in the pathogenesis of pulmonary hypertension. Circ Res 2006; 98: 209-217. 
69 Toshner M, Voswinckel R, Southwood M, et al. Evidence for dysfunction of endothelial progenitors in pulmonary arterial hypertension. Am J Respir Crit Care Med 2009; 180: 780-787.

70 Davie NJ, Crossno JT Jr, Frid MG, et al. Hypoxia-induced pulmonary artery adventitial remodeling and neovascularization: contribution of progenitor cells. Am J Physiol Lung Cell Mol Physiol 2004; 286: L668-L678.

71 Hayashida K, Fujita J, Miyake Y, et al. Bone marrow-derived cells contribute to pulmonary vascular remodeling in hypoxia-induced pulmonary hypertension. Chest 2005; 127: 1793-1798.

72 Marsboom G, Pokreisz P, Gheysens O, et al. Sustained endothelial progenitor cell dysfunction after chronic hypoxia-induced pulmonary hypertension. Stem Cells 2008; 26: 1017-1026.

73 Satoh K, Kagaya Y, Nakano M, et al. Important role of endogenous erythropoietin system in recruitment of endothelial progenitor cells in hypoxia-induced pulmonary hypertension in mice. Circulation 2006; 113: 1442-1450.

74 Raoul W, Wagner-Ballon O, Saber G, et al. Effects of bone marrowderived cells on monocrotaline- and hypoxia-induced pulmonary hypertension in mice. Respir Res 2007; 8: 8.

75 Zhao YD, Courtman DW, Deng Y, et al. Rescue of monocrotalineinduced pulmonary arterial hypertension using bone marrowderived endothelial-like progenitor cells: efficacy of combined cell and eNOS gene therapy in established disease. Circ Res 2005; 96 : 442-450.

76 Baber SR, Deng W, Master RG, et al. Intratracheal mesenchymal stem cell administration attenuates monocrotaline-induced pulmonary hypertension and endothelial dysfunction. Am J Physiol Heart Circ Physiol 2007; 292: H1120-H1128.

77 Nagaya N, Kangawa K, Kanda M, et al. Hybrid cell-gene therapy for pulmonary hypertension based on phagocytosing action of endothelial progenitor cells. Circulation 2003; 108: 889-895.
78 Dimmeler S, Zeiher AM. Cell therapy of acute myocardial infarction: open questions. Cardiology 2009; 113: 155-160.

79 Fadini GP, Agostini C, Avogaro A. Autologous stem cell therapy for peripheral arterial disease. Meta-analysis and systematic review of the literature. Atherosclerosis 2009; [Epub ahead of print. DOI:10.1016/J.ATHEROSCLEROSIS.2009.08.033].

80 Clavel C, Verfaillie CM. Bone-marrow-derived cells and heart repair. Curr Opin Organ Transplant 2008; 13: 36-43.

81 Wang XX, Zhang FR, Shang YP, et al. Transplantation of autologous endothelial progenitor cells may be beneficial in patients with idiopathic pulmonary arterial hypertension: a pilot randomized controlled trial. J Am Coll Cardiol 2007; 49: 1566-1571.

82 Zhu JH, Wang XX, Zhang FR, et al. Safety and efficacy of autologous endothelial progenitor cells transplantation in children with idiopathic pulmonary arterial hypertension: open-label pilot study. Pediatr Transplant 2008; 12: 650-655.

83 Aicher A, Heeschen C, Mildner-Rihm C, et al. Essential role of endothelial nitric oxide synthase for mobilization of stem and progenitor cells. Nat Med 2003; 9: 1370-1376.

84 Dimmeler S, Aicher A, Vasa M, et al. HMG-CoA reductase inhibitors (statins) increase endothelial progenitor cells via the PI 3-kinase/Akt pathway. J Clin Invest 2001; 108: 391-397.

85 Rhodes CJ, Davidson A, Gibbs JS, et al. Therapeutic targets in pulmonary arterial hypertension. Pharmacol Ther 2009; 121: 69-88.

86 Sun $\mathrm{X}, \mathrm{Ku}$ DD. Rosuvastatin provides pleiotropic protection against pulmonary hypertension, right ventricular hypertrophy, and coronary endothelial dysfunction in rats. Am J Physiol Heart Circ Physiol 2008; 294: H801-H809.

87 Foresta C, De Toni L, Di Mambro A, et al. The PDE5 inhibitor sildenafil increases circulating endothelial progenitor cells and CXCR4 expression. J Sex Med 2009; 6: 369-372. 